\title{
Potential spreading risk of an invasive snail species (Pomacea canaliculata) in freshwater habitats of Asia
}

\author{
Wasana de Silva ${ }^{1,2}$, Te Cao ${ }^{1}$, Zihao Wen ${ }^{1,2}$, Xiaolin Zhang ${ }^{1, *}$ and Leyi Ni ${ }^{1}$ \\ ${ }^{1}$ Donghu Experimental Station of Lake Ecosystem, State Key Laboratory of Freshwater Ecology and Biotechnology, Institute of Hydrobiology, \\ The Chinese Academy of Sciences, Wuhan, China \\ ${ }^{2}$ University of Chinese Academy of Sciences, Beijing, China
}

\begin{abstract}
The invasive success of the freshwater snail species (Pomacea canaliculata) continues to wreak havoc around the world. The present study was initiated to analyse spatial trend and associated environmental conditions related to the invasive success of $P$. canaliculata in Asia. Systematic searches were performed to identify relevant studies through different databases, and appropriate statistical methods like spatial autocorrelation, standard deviational ellipse method and PCA were used to generate new knowledge on this species. The potential invasive range of this species is between $40^{\circ} \mathrm{N}$ and $40^{\circ} \mathrm{S}$ lat. The present study reveals that the spatial distribution of $P$. canaliculata is most significantly correlated with human population density, followed by humidity, temperature and precipitation. Moreover, the grazing rates are dramatically affected by nutrient content of freshwater macrophytes. Spatial autocorrelation analysis result indicates clustered dispersion pattern of this snail, and standard deviational ellipse depicts the invasion trend of $P$. canaliculata moving from East Asia to potential areas in South and West Asia. We therefore conclude that $P$. canaliculata is likely to be the 'next harmful visitor' to South and West Asian countries.
\end{abstract}

Keywords. Freshwater macrophytes, invasive species, Pomacea canaliculata, spreading risk.

POMACEA CANALICULATA (also known as golden apple snail) is a native species of South America ${ }^{1-3}$, and was first introduced to Asia in 1980 through South China from Argentina for aquaculture purposes ${ }^{4}$. Later, $P$. canaliculata was introduced to southeast Asia primarily for aquaculture and food purposes ${ }^{5-7}$. After introduction, this species thrived in freshwater habitats of marshes, ponds and ditches ${ }^{5}$ and has become a significant pest in its nonnative ranges causing severe impacts on freshwater ecosystems ${ }^{4,8,9}$. As a macrophyte grazer, this species has caused serious damage to freshwater wetlands in terms of diminishing wetland functions and services ${ }^{10}$. This invasive species has caused substantial economic loss to

*For correspondence. (e-mail: zhangxl@ihb.ac.cn) countries in Southeast and East Asia in particular ${ }^{3}$. Furthermore, $P$. canaliculata is also an intermediate host for Angiostrongylus vasorum, which causes infectious disease of human eosinophilic encephalitis ${ }^{6}$. Based on the damage caused to freshwater ecosystems, $P$. canaliculata is considerd as one of the worst invasive species in the world $^{1}$ (Figure 1).

The high rate of survival and fecundity enables successful establishment of a species in a new environment ${ }^{11}$. In Thailand, $P$. canaliculata was able to survive in the new environment by outcompeting the native species, i.e. Thai native snail (Pila scutata), and thus become a successful invader throughout that country ${ }^{10}$. Rapid growth and distribution of $P$. canaliculata in Southeast Asia suggest that phenotypic plasticity of this species could support its successful invasion in this region ${ }^{12}$. As phenotypic plasticity is a result of natural selection, we can identify the areas with high risk of being invaded by this species by summarizing the general characteristics of invaded habitats. Such identification and prediction of potential areas of invasion of this snail will be important for a better understanding to implement management activities and policies.

In this study we used quantitative forecasting methods that link with spatial statistics to predict the directional trend to spatial distribution of this snail. As such, we focus on several aspects: (1) the dispersal pattern of $P$. canaliculata in the global range; (2) the distribution variation in recent years; (3) the key environmental factors that will affect invasion success and regulate spatial distribution pattern, and (4) the potential habitats of the snail.

\section{Methods}

A systematic survey was carried out using scientific databases and search engines, followed by relevant analysis. The keyword combinations of $P$. canaliculata* OR apple snail AND distribution* AND freshwater* AND vegetation* OR macrophytes* AND growth* AND plasticity* in the title were used. By this method, comprehensive 

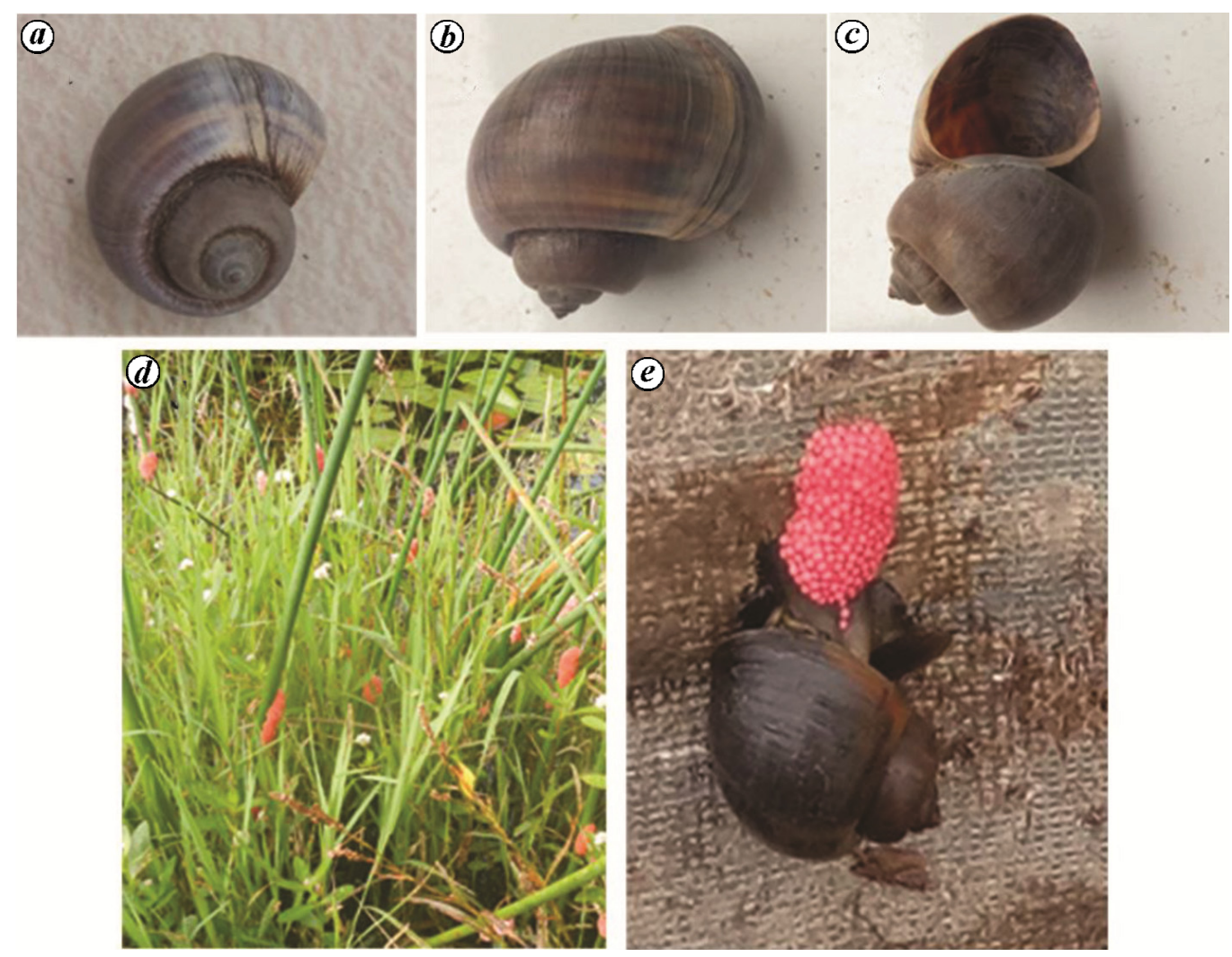

Figure 1. Pomacea canaliculata in the field: $\boldsymbol{a}$, top view; $\boldsymbol{b}$, dorsal view; $\boldsymbol{c}$, ventral view; $\boldsymbol{d}$, egg clutches attached to macrophytes; $\boldsymbol{e}$, depositing egg clutch on mesh.

studies (88 scientific articles and reports) which were carried out from 1994 through 2017 were identified. Approximately $82.56 \%$ of the published studies was carried out between 2010 and 2015, of which 37\% was primarily done in East Asian counties.

\section{Data extraction method}

Based on the vast data of this species, we reveal the global distribution pattern of $P$. canaliculata and crucial factors responsible for its drastic distribution in Southeast and East Asia. Locations of the snails collected from different articles and web pages which cited them were used to identify habitats of snails and hence to prepare snail distribution maps. Google Earth was used to identify latitudes and longitudes, when such data were not provided. Arc Map software (version 10.2.2) was used to draw distribution maps. Maps available on ArcGIS on-line and satellite images were used to extract statistics on human population density, rainfall, average temperature and minimum temperature of the habitats of this snail. Elevation data were extracted using ASTER GDEM of USGS Earth Explorer ${ }^{13}$. Average annual relative humidity of the identified habitats was extracted from Climate Research unit, University of East Anglia, $\mathrm{UK}^{14}$. Further, data extraction from figures in peer-reviewed publications was carried out using Plot Digitizer software ${ }^{15}$.

\section{Statistical analysis}

Principle component analysis (PCA) was performed on environmental parameters and further on properties of plants related to feeding preference of this snail to explore the major factors that determine the invasive success of the snail. Spatial autocorrelation, if any, out in the distribution of this snail was determined using Moran I statistics. Thus, Moran's I value was used to determine whether the pattern was clustered, dispersed or random. The Moran's I index for spatial autocorrelation for a given variable is defined as

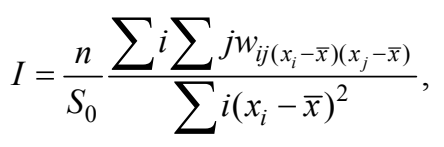

where $n$ is the total number of features indexed by $i$ and $j$, $x$ the variable of interest; $\bar{x}$ the mean of $x, S_{0}$ the aggregation of all spatial weights and $w_{i j}$ is the spatial weight between features $i$ and $j$.

Standard deviational ellipse (SDE) method was used to reveal directional trend and hence degree of spatial dispersion of invasion of $P$. canaliculata across different geographical areas. In the present study, we considered one standard deviation to demonstrate the distribution that accounted for $68 \%$ of all input variables of snail densities and environmental conditions. 
SDE is represented as

$$
\begin{aligned}
& \operatorname{SDE}_{x}=\sqrt{\sum_{i=1}^{n} \frac{\left(x_{i}-\bar{X}\right)^{2}}{n}}, \\
& \operatorname{SDE}_{y}=\sqrt{\sum_{i=1}^{n} \frac{\left(y_{i}-\bar{Y}\right)^{2}}{n}},
\end{aligned}
$$

where $x_{i}$ and $y_{i}$ are the coordinates of feature $i,\{\bar{X}, \bar{Y}\}$ depicts mean centre of the features, and $n$ depicts the total number of features.

The angle rotation of SDE is given by the following equations

$$
\begin{aligned}
& \tan \theta=\frac{A+B}{C}, \\
& A=\left(\sum_{i=1}^{n} \tilde{X}_{i}^{2}-\sum_{i=1}^{n} \tilde{Y}_{i}^{2}\right), \\
& B=\sqrt{\left(\sum_{i=1}^{n} \tilde{X}_{i}^{2}-\sum_{i=1}^{n} \bar{Y}_{i}^{2}\right)^{2}+4\left(\tilde{X}_{i}, \tilde{Y}_{i}\right)^{2},} \\
& C=2 \sum_{n=1}^{n} \tilde{X}_{i}, \tilde{Y}_{i},
\end{aligned}
$$

where $\tilde{X}_{i}$ and $\tilde{Y}_{i}$ are deviations of the $x$ and $y$ coordinates from the mean centre.

The standard deviation for the $x$ and $y$ coordinates is given as

$$
\begin{aligned}
& \sigma_{x}=\sqrt{2} \sqrt{\sum_{i=1}^{n} \frac{\left(\tilde{x}_{i} \cos \theta-\tilde{y}_{i} \sin \theta\right)^{2}}{n}} \\
& \sigma_{y}=\sqrt{2} \sqrt{\sum_{i=1}^{n} \frac{\left(\tilde{x}_{i} \sin \theta-\tilde{y}_{i} \cos \theta\right)^{2}}{n}} .
\end{aligned}
$$

\section{Results}

Figure 2 shows the distribution pattern of $P$. canaliculata across the world. It is preferentially distributed across regions with an average temperature of $20-25^{\circ} \mathrm{C}$, and minimum temperature of $10-15^{\circ} \mathrm{C}$ (Figure 3). Moreover, noticeable snail population density was observed in areas of average annual precipitation of $1500 \mathrm{~mm}$.

In Figure 4, the first three axes explain 96\% (49.39\%+ $30.57 \%+16.68 \%$ ) of the total variation in environmental data. There is significant positive correlation between snail density and human population density. Furthermore, snail density is also positively correlated with humidity, temperature and precipitation. The result of spatial autocorrelation statistics shows significant spatial correlation in snail density in different geographical regions. The Moran's I value is $1.36(Z=3.5 ; P<0.5)$, suggesting that distribution of $P$. canaliculata was more spatially clustered.

Figure 5 shows the directional trend and dispersion pattern of $P$. canaliculata in different geographical regions. SDE reveals directional trends of how snails are spreading based on environmental conditions. The orientation of the ellipse indicates that the distribution of $P$. canaliculata is more likely to be established in freshwater areas of tropical and subtropical regions in South and West Asia.

Feeding preference of the snail on various plant species differs. Certain plant properties are important in determining feeding preference of the snail (Figures 6 and 7). In Figure 7 , the first two axes explain 91\% (0.7423+ 0.1683 ) of the total variation in the considered properties of plants. Feeding rates of snails are highly influenced by phosphorus content, followed by nitrogen content in plants. The grazing rates are dramatically affected by the phenolic and dry matter content of plants (Figure 7$)^{16}$.

\section{Discussion}

Environmental factors are key determinants of the spatial distribution of species all over the world ${ }^{17}$. Climate change is one of the leading factors determining the distribution pattern of species across the world. So changes in temperature and rainfall influence the spreading of biological invaders ${ }^{18}$.

According to our results, $P$. canaliculata invaded and thrived in ecoregions of temperate coastal rivers and floodplain rivers in some areas of Europe and East Asia, and tropical floodplain rivers and wetlands in East Asia. However, native distribution of snails is mostly confined to areas of temperate coastal rivers, and tropical and subtropical upland rivers, i.e. between $20^{\circ} \mathrm{S}$ and $40^{\circ} \mathrm{S}$ lat. However, invasion was also recorded between $40^{\circ} \mathrm{N}$ and $40^{\circ} \mathrm{S}$ lat (Figure 2 ). And its invasion prefers to low elevation $(<50 \mathrm{~m})$ areas (Figure $3 e)$. Comparing with its native distribution (tropical, subtropical and temperate wetlands in South America), its invasion expands to tropical, subtropical and temperate wetlands both in south and north hemisphere.

The significant positive correlation between snail density and human population density indicated that introduction, colonization and dispersal of the snail are highly affected by human activities. A few freshwater snails are traditionally delicious cuisine in some countries ${ }^{6} . P$. canaliculata was also introduced into East Asia in 1980 as a supplementary protein source ${ }^{10}$. Our analysis of the 

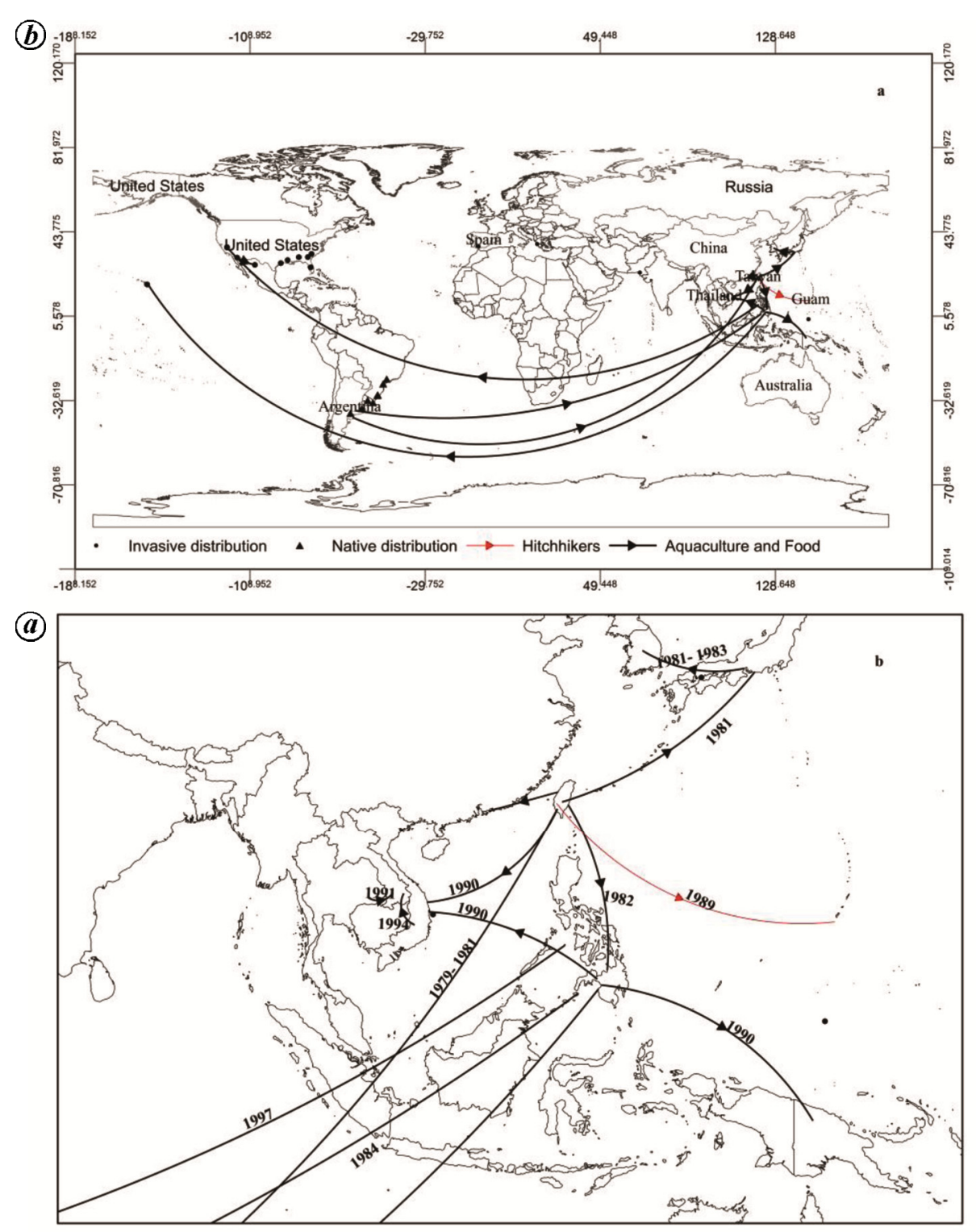

Figure $2 \boldsymbol{a}, \boldsymbol{b}$. Distribution of $P$. canaliculata across the world. (Map drawn using freely available GIS data $^{33}$ with Arc GIS version 10.2.2.)

distribution pattern is also in accordance with this result. Another factor crucial to invasive success of this species is relative humidity (Figures $3 d$ and 4). Dramatically high densities of snail occurred in habitats with relative humidity of $60-80 \%$. It has been reported that the survival of this snail is significantly correlated with relative humidity, and the optimal value is $59.8-77.1 \%$ (mean $69.3 \%)^{8}$.

The present study revealed that snail density is correlated with temperature. This snail species can tolerate a wide range of temperatures, from $10^{\circ} \mathrm{C}$ to $28^{\circ} \mathrm{C}$. An earlier study also indicated that survival of this snail was correlated with temperature, and significant growth was observed at temperature between $16.6^{\circ} \mathrm{C}$ and $28.3^{\circ} \mathrm{C}$ (mean $\left.22.4^{\circ} \mathrm{C}\right)^{8}$. It was reported that survival rates of these snails were negatively correlated with temperature $(100 \%$ for $15^{\circ} \mathrm{C}$ and $20^{\circ} \mathrm{C}, 95.83 \%$ for $25^{\circ} \mathrm{C}$ and $87.5 \%$ for $\left.30^{\circ} \mathrm{C}\right)^{19}$. Although this snail generally grows at $10^{\circ}-28^{\circ} \mathrm{C}$ (Figure $3 a)^{20}$, a few previous studies revealed that this snail can even survive in dramatic low temperatures, i.e. below $0^{\circ} \mathrm{C}$ (Figure $\left.3 b\right)^{9}$. Such a result indicates the overwintering ability of this species in subtropical and temperate regions. Potential distribution of high biomass of $P$. canaliculata was predicted at coastal and inland Mediterranean areas in Europe (Figure 2) ${ }^{7}$. Interestingly, they have the adaptive capability of resistance to warmer climate to a certain extent by inducing several proteins to repair damage caused by heat stress ${ }^{21}$.

The maturity ages of $P$. canaliculata present variation according to different environments. A laboratory experiment done in Hawaii, USA, revealed that maturity age of $P$. canaliculata was 10 months, while it was 2 years 

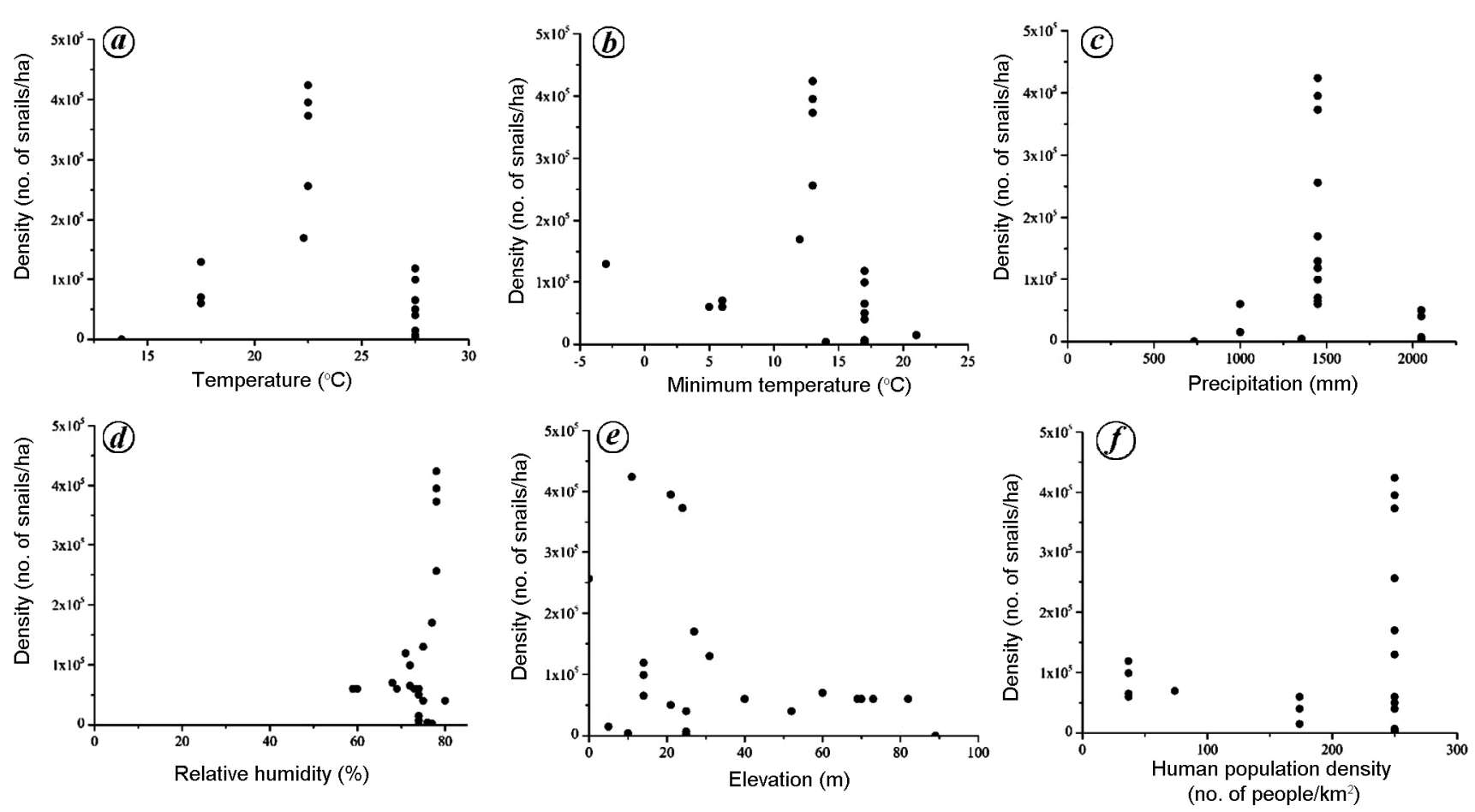

Figure 3. Density of $P$. canaliculata relevant to different environmental factors: $\boldsymbol{a}$, temperature; $\boldsymbol{b}$, minimum temperature; $\boldsymbol{c}$, precipitation; $\boldsymbol{d}$, relative humidity; $\boldsymbol{e}$, elevation; $\boldsymbol{f}$, human population density.
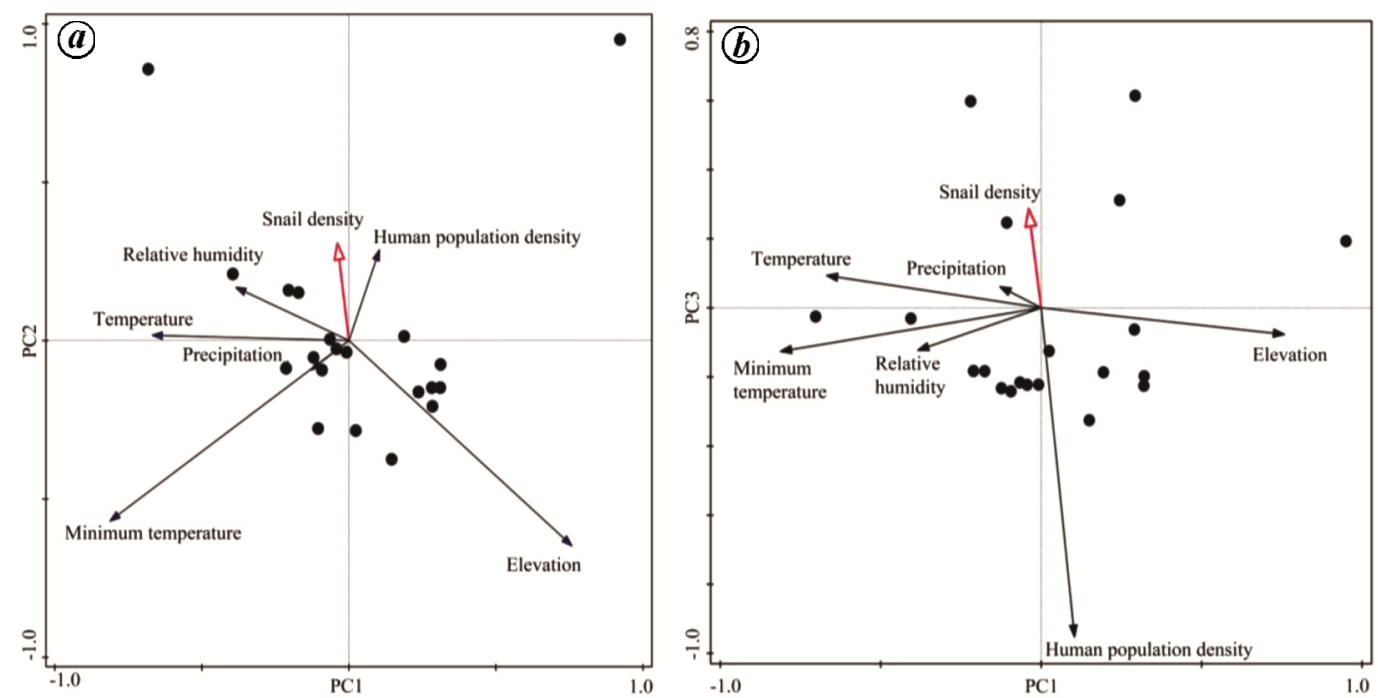

Figure 4. Principal component analyses (PCA) tri-plot showing (a) axes 1 and 2 and (b) axes 1 and 3 of PCA ordination of environmental parameters (black arrows) and snail density (red arrow). Filled circles show summary of the considered variables.

in Argentina ${ }^{22}$. The maturity age in Southeast Asian countries such as Philippines and Malaysia was 3-7 months $s^{3,17}$. These results indicate that the maturity age could be self-regulated according to different environments and the changed maturity period induced population explosion in the invaded habitats rather than the native habitats. Breeding in Pomacea species could be influenced by temperature and relative humidity ${ }^{23}$. In
Southeast Asia, the fecundity of $P$. canaliculata was higher with 2400-8700 eggs/year (ref. 3), while in the US fecundity was about 4355 eggs/year (ref. 24). The average number of eggs in per clutch is highly variable in the native and invaded ranges, i.e. 42 eggs/clutch in the eastern coast of Uruguay, 68-208 eggs/clutch in the Philippines, and 97 eggs/clutch in both Hawaii and Taiwan Island ${ }^{4,25}$. 
According to $\mathrm{IPCC}^{26}$, by the end of this century, global mean temperature will increase by $2.6^{\circ}-4.8^{\circ} \mathrm{C}$. It is evident that the Indian sub-continent will face more warming impact and hence there will be relatively high temperature in winter ${ }^{27}$. As temperature increases, the species will move from their original ranges ${ }^{28,29}$. Based on our results, this species shows enhanced ability of growth and distribution in the invaded areas, especially with greater capacity to spread in tropical and subtropical areas of Asia. Considering the climate change trend and environment characters, we further speculate that $P$. canaliculata will have a trend of moving to potential habitats in South and West Asian countries (Figure 5).

The population size of the species could be determined by its consumption of food types and proportion of its consumption $^{30}$. P. canaliculata is a macro-phytophagous snail. Its nutrient utilization ability varies with the type of nutrients available in plants. Chemical factors, such as the amount of phenolic compound, dry matter content, nitrogen and phosphorus content affect the feeding of this snail ${ }^{17,32}$. The feeding rates were dramatically influenced by phosphorus content, followed by nitrogen content in plants. Macrophytes containing more phenolic and dry matter, and greater physical toughness in terms of more lignin and cellulose are less palatable $\mathrm{e}^{16,31,32}$. Freshwater plants like Ipomoea, Amaranthus and Apium (Figures 6 and 7)

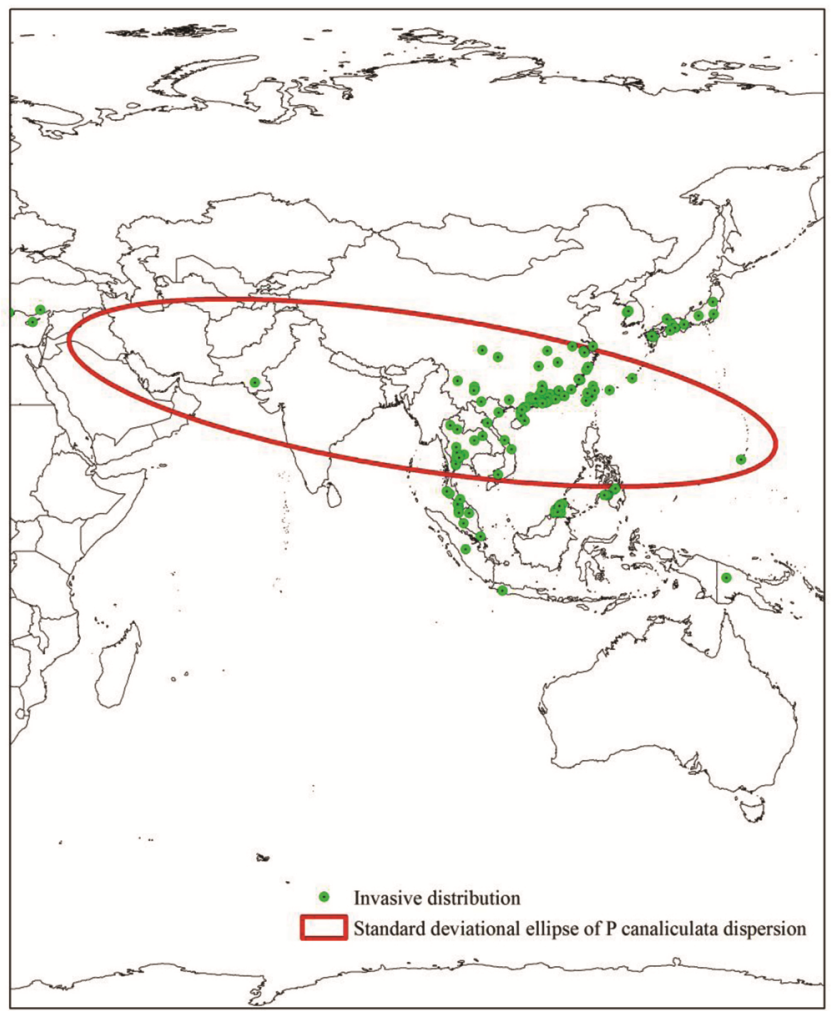

Figure 5. Directional trend of $P$. canaliculata distribution in different geographical areas. (Map drawn using freely available GIS data ${ }^{16}$ with Arc GIS version 10.2.2.) are generally higher in nutrient content in terms of nitrogen and phosphorus, while lesser in physical toughness. Hence these macrophyte species are more palatable to $P$. canaliculata. Furthermore, Eichornia and Amaranthus are also invasive weeds which have cosmopolitan distribution in freshwater bodies around the world. Our results indicated the potential damages by $P$. canaliculata to wetlands rely on the macrophyte community composition $^{16}$. Previous studies further revealed that nitrogen and phosphorus contents in edible plants were positively correlated with growth and fecundity of the snail ${ }^{31}$. Additionally, females can adjust the spawning time based on
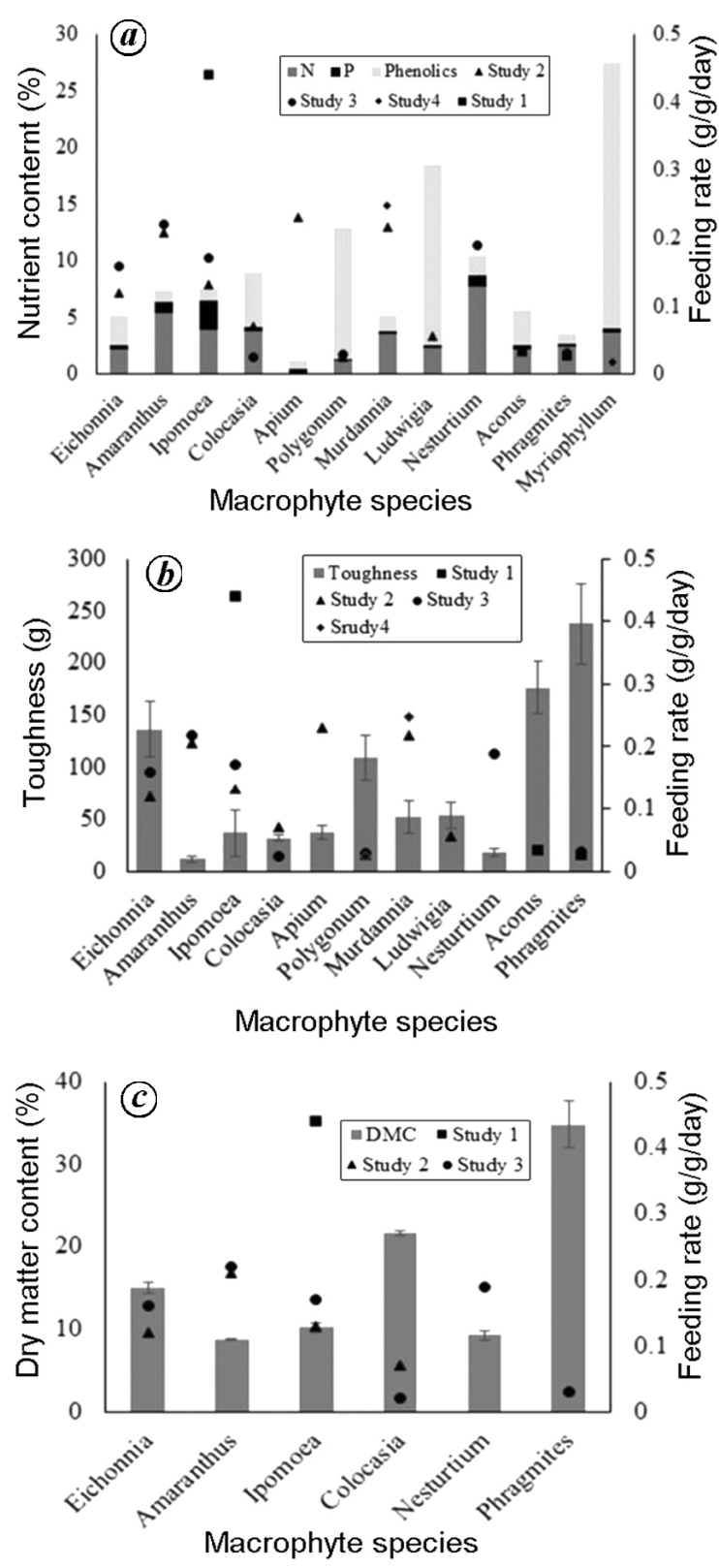

Figure 6. Properties of freshwater macrophytes: (a) nutrients, (b) toughness and (c) dry matter content and feeding rates of $P$. canaliculata.

CURRENT SCIENCE, VOL. 117, NO. 6, 25 SEPTEMBER 2019 


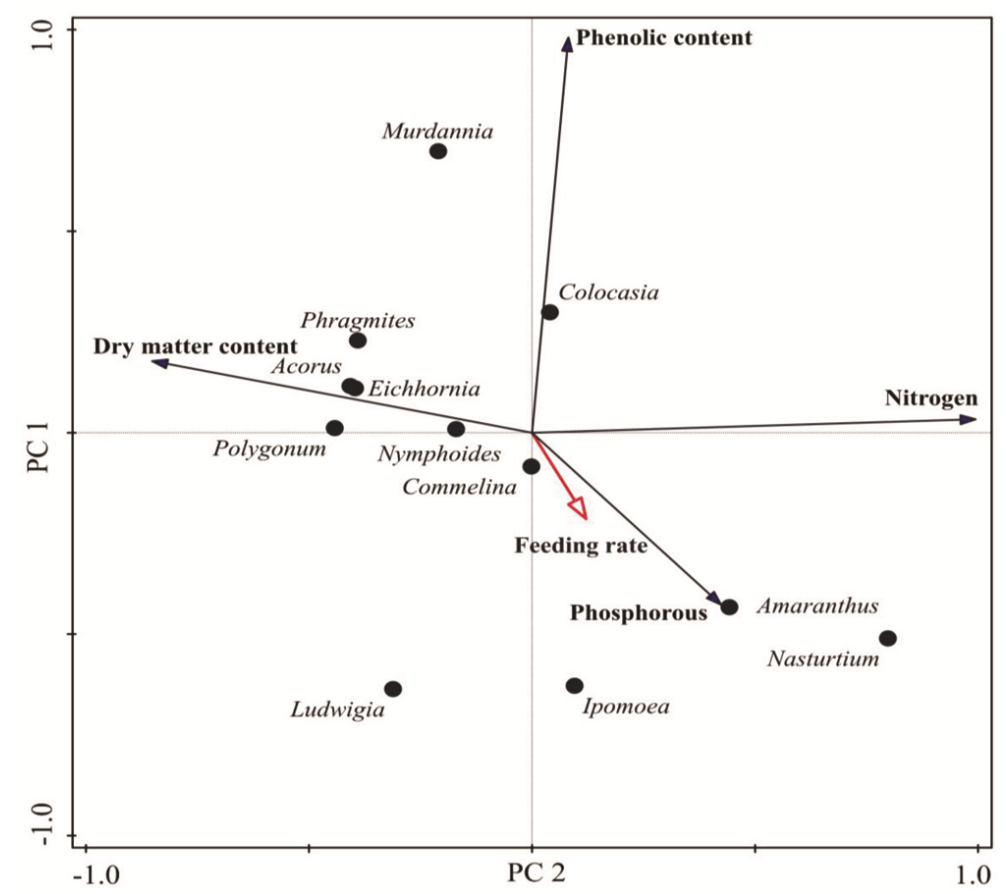

Figure 7. PCA bi-plot showing axes 1 and 2 of PCA ordination of properties of plants (black arrows) and feeding rates (red arrow). Filled circles show the considered plant species.

the feeding nutrient level, which indicates that dietary flexibility also attributes to their rapid and successful distribution. The present study therefore ascertains the current spatial variation and future trend of invasion of $P$. canaliculata in Asia.

\section{Conclusion}

Growth and survival of $P$. canaliculata vary considerably with environmental factors and hence these factors determine the spatial distribution pattern of $P$. canaliculata across different regions in the world. Feeding preference of this species is determined by some traits of plants. Interestingly, the results of this study suggest that human population density, followed by relative humidity, temperature and precipitation affect snail density and thus facilitate its distribution. Thus, rapid distribution of $P$. canaliculata has occurred across the regions in humid Asia compared to other species living in the same habitats. Furthermore, P. canaliculata has the ability to invade rapidly in South and West Asia, in particular.

Disclosure statement: No potential conflict of interest was reported by the authors.

1. Lowe, S., Browne, M., Boudjelas, S. and Poorter De, M., 100 of the World's Worst Invasive Alien Species: A Selection from the Global Invasive Species Database, IUCN, 2000; http://www. issg.org/pdf/publications/worst_100/english_100_worst (accessed on 18 August 2016).
2. Cabi.org, Pomacea canaliculata (golden apple snail); http:// www.cabi.org/isc/datasheet/68490 (accessed on 3 October 2016).

3. Arfan, A. G., Muhamad, R., Omar, D., Azwady, A. A. and Manjeri, G., Comparative life cycle studies of Pomacea maculata and Pomacea canaliculata on rice (Oryza sativa). Pak. J. Agric. Sci., 2015, 52(4), 1075-1079.

4. Wu, J. Y., Wu, Y. T., Li, M. C., Chiu, Y. W., Liu, M. Y. and Liu, L. L., Reproduction and juvenile growth of the invasive apple snails Pomacea canaliculata and $P$. scalaris (Gastropoda: Ampullariidae) in Taiwan. Zool. Stud., 2011, 50(1), 61-68.

5. Rawlings, T. A., Hayes, K. A., Cowie, R. H. and Collins, T. M., The identity, distribution, and impacts of non-native apple snails in the continental United States. BMC Evol. Biol., 2007, 7(97), $1-14$.

6. Lv, S., Zhang, Y., Steinmann, P., Guo, Y., Yang, K., Zhou, X. and Utzinger, J., The emergence of angiostrongyliasis in the People's Republic of China: the interplay between invasive snails, climate change and transmission dynamics. Freshwater Biol., 2011, 56, 717-734.

7. EFSA Panel on Plant Health, Scientific opinion on the environmental risk assessment of the apple snail for the EU. EFSA, 2014, 12(4), 1-97.

8. Trexler, C. M., Biology, ecology and control of the invasive channeled apple snail, Pomacea canaliculata. M Sc Dissertation, University of Central Florida, USA, 2011.

9. Yoshida, K., Matsukura, K., Cazzaniga, N. J. and Wada, T., Tolerance to low temperature and desiccation in two invasive apple snails, Pomacea canaliculata and P. maculata (Caenogastropoda: Ampullariidae), collected in their original distribution area (northern and Central Argentina). J. Mollus. Stud., 2014, 80, 62-66.

10. Chaichana, R. and Sumpana, T., The potential ecological impact of the exotic snail Pomacea canaliculata on the Thai native snail Pila Scutata. Sci. Asia, 2014, 40, 11-15.

11. Abhilasha, D. and Joshi, J., Enhanced fitness due to higher fecundity, increased defence against a specialist and tolerance 
towards a generalist herbivore in an invasive annual plant. J. Plant Ecol., 2009, 2(2), 77-86.

12. Estebenet, A. L. and Martín, P. R., Shell interpolation variation and its origin in Pomacea canaliculata (Gastropoda: Ampullariidae) from southern Pampas, Argentina. J. Mollus. Stud., 2003, 69, 301-310.

13. EarthExplorer, http://earthexplorer.usgs.gov (accessed on 2 November 2016).

14. Climate Research Unit, University of East Anglia, UK; http:// www.cru.uea.ac.uk/ markn/cru05/cru05 intro.html (accessed on 27 November 2016).

15. Boleman, M., Ronhovde, P. and Sanders, J., Plot Digitizer Software, Department of Physics, University of Alabama, USA, 2002.

16. Qiu, J. and Kwong, K., Effects of macrophytes on feeding and life-history traits of the invasive apple snail Pomacea canaliculata. Freshwater Biol., 2009, 54, 1720-1730.

17. Teo, S. S., Biology of the golden apple snail, Pomacea canaliculata (Lamarck, 1822), with emphasis on responses to certain environmental conditions in Sabah, Malaysia. Mollus. Res., 2004, 24, 139-148.

18. Dukes, J. S. and Mooney, H. A., Does global change increase the success of biological invaders? Trends Ecol. Evol., 1999, 14(4), $135-139$.

19. Seuffert, M. E. and Martín, P. R., Distribution of the apple snail Pomacea canaliculata in Pampean streams (Argentina) at different spatial scales. Limnologica, 2013, 43, 91-99.

20. Memon, U. N., Baloch, W. A., Tunio, G. R., Korai, A. L. and Pirzada, A. J., Food, feeding and growth of golden apple snail Pomacea canaliculata, Lamarck (Gastropoda: Ampullariidae). Sindh Univ. Res. J., 2011, 43(1), 25-28.

21. $\mathrm{Mu}, \mathrm{H}$. et al., Genetic basis of differential heat resistance between two species of congeneric freshwater snails: insights from quantitative proteomics and base substitution rate analysis. J. Proteome Res., 2015, 14(10), 4296-4308.

22. Lach, L., Britton, D. K., Rundell, R. J. and Cowie, R. H., Food preference and reproductive plasticity in an invasive freshwater snail. Biol. Invasions, 2000, 2, 279-288.

23. Ramakrishnan, V., Salinity, pH, temperature, desiccation and hypoxia tolerance in the invasive freshwater apple snail Pomacea insularum. Ph D dissertation, University of Texas, USA, 2007.

24. Keller, R., Lodge, D. M., Keller, R. P., Drake, J. M. and Lodge, D. M., Fecundity as a basis for risk assessment of nonindigenous freshwater molluscs. Conserv. Biol., 2007, 21(1), 191-200.
25. Kyle, C. H., Plantz, A. L., Shelton, T. and Burks, R. L., Count your eggs before they invade: identifying and quantifying egg clutches of two invasive apple snail species (Pomacea). PLoS ONE, 2013, 8(10), 1-11.

26. IPCC, Climate Change 2014: Synthesis Report, 2014; http:// www.ipcc.ch/report/ar5/syr/ (accessed on 27 March 2017).

27. Kumar, N., Tischbein, B., Kusche, J., Laux, P., Beg, M. K. and Bogardi, J. J., Regional studies impact of climate change on water resources of upper Kharun catchment in Chhattisgarh, India. J. Hydrol. Reg. Stud., 2017, 13, 189-207.

28. Thomas, C. D., Harte, J., Ostling, A., Green, J. L. and Kinzig, A., Climate change and extinction risk. Nature, 2004, 427, 145-148.

29. Vasco, P. and Herriko, E., Niche dynamics in space and time. Trends Ecol. Evol., 2008, 149-158.

30. Lacher, T. E. R., Willig, M. R. and Mares, M. A., Food preference as a function of resource abundance with multiple prey types: an experimntal analysis of optimul foraging theory. Am. Nat., 1982, 120(3), 297-316.

31. Yam, R. S. W., Fan, Y. and Wang, T., Importance of macrophyte quality in determining life-history traits of the apple snails Pomacea canaliculata: implications for bottom-up management of an invasive herbivorous pest in constructed wetlands. Int. J. Environ. Res. Public Health, 2016, 13, 1-17.

32. Wong, P. A. K. K. I., Liang, Y. A. N., Liu, N. G. A. Y. and Qiu, J., Palatability of macrophytes to the invasive freshwater snail Pomacea canaliculata: differential effects of multiple plant traits. Freshwater Biol., 2010, 55, 2023-2031.

33. World Gis data, http://www.mappinghacks.com/data (accessed on 27 March 2018).

ACKNOWLEDGEMENTS. This research work was supported by the Major Science and Technology Programme for Water Pollution Control and Treatment (2015ZX07503-005), the National Science Foundation of China (31870446), Natural Science Foundation of Jiangxi Province (2015ZBBF6008) and State Key Laboratory of Freshwater Ecology and Biotechnology (2016FBZ08), China.

Received 31 July 2018; revised accepted 11 June 2019

doi: $10.18520 / \mathrm{cs} / \mathrm{v} 117 / \mathrm{i} 6 / 1071-1078$ 